\title{
A Method for Smoothly Disengaging the Load- Holding Valves of Energy-Efficient Electro-Hydraulic Systems
}

\author{
Daniel Hagen ${ }^{1 *}$ and Damiano Padovani ${ }^{1}$ \\ 1 De partment of Enginee ring Sciences, University of Agder, 4879 Grimstad, Norway; daniel.hagen@uia.no \\ (D.H.); damiano.padovani@uia.no (D.P.) \\ * Correspondence: daniel.hagen@uia.no
}

\begin{abstract}
A novel self-contained, electro-hydraulic cylinder drive capable of passiveload-holding, four-quadrant operations, and energy recovery was presented recently and implemented successfully. This solution improved greatly the energy efficiency and motion con trol in comparison to state-of-the-art, valve-controlled systems ty pically used in mobile and offshore applications. The passive load-holding function was realized by two pilot-operated check valves placed on the cylinder ports, where their pilot pressure is selected by a dedicated on/off electrovalve. These valves can maintain the actuator position without consuming energy, as demonstrated on a single-boom crane. However, a reduced drop of about $1 \mathrm{~mm}$ was observed in the actuator position when the load-holding valves are disengaged to enable the piston motion using closed-loop position control. Such a sudden variation in the piston position that is triggered by switching the load-holding valves can increase up to $4 \mathrm{~mm}$ when open-loop position control is chosen. For these reasons, this research paper proposes an improved control strategy for disengaging the passive load-holding functionality smoothly (i.e., by removing this unw anted drop of the piston). A two-step pressure control strategy is used to build up pressure before disengaging the pilot-operated check valves. The proposed experimental validation of this method eliminates the piston position's drop highlighted before and improves the motion control when operating the crane in open-loop position control. Theses outcomes benefit those systems where the kinematics amplifies the piston motion significantly (e.g., in aerial platforms) increasing, therefore, the operational safety.
\end{abstract}

Keywords: linear actuators; self-contained cylinders; electro-hydraulic systems; passive loadholding; load-carrying applications; energy recovery; energy efficiency; pressure control

\section{Introduction}

Hydraulic cylinders are commonplace in many fields of industry due to their high-force capability. Valve-controlled systems normally drive these actuators using multiple architectures [1]. The ongoing interest tow ard energy savings and plug-and-play installation is making valveless, selfcontained solutions an alternative technology. Removing the fluid throttling in control valves improves the energy efficiency greatly [2]-[8]. Proposing self-sufficient, electro-hydraulic assemblies with a sealed reservoir, arranged in closed-circuit configuration, and with a wired connection to the electric grid facilitates the commissioning enormously. Solutions with a single positive-displacement pump/motor [9]-[16], and alternatives with two units were investigated [7], [17]-[19]. These different versions were mainly proposed to manage the differential flow dictated by asymmetric cylinders, that can be compensated in multiple ways [20]. How ever, only a very few solutions specifically address the load-holding capability [14], [15], [16], [18], [19]. In these throttleless architectures, energy can be recovered in case of overrunning loads so that there is only the need for passive load-holding (i.e., maintaining a given piston position without consuming any 
power). This research paper focuses on the system layout presented in [15], where a reduced drop in the actuator position was observed when the load-holding valves (LHVs) are disengaged to enable the piston motion. For this reason, an improved control strategy for smoothly disengaging the passive load-holding functionality is investigated.

\section{Materials and Methods}

An experimental test-bed of a self-contained, electro-hydraulic cylinder with passive loadholding capability was recently built at the University of Agder to drive a single-boom crane. Figure 1 depicts the simplified schematic of this system and its implementation. More details about the components and the system functioning are given in [15], [21].

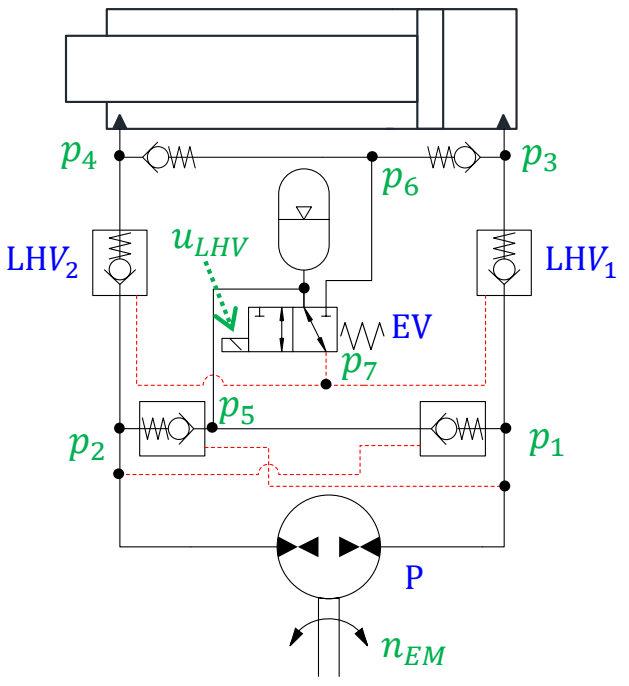

(a)

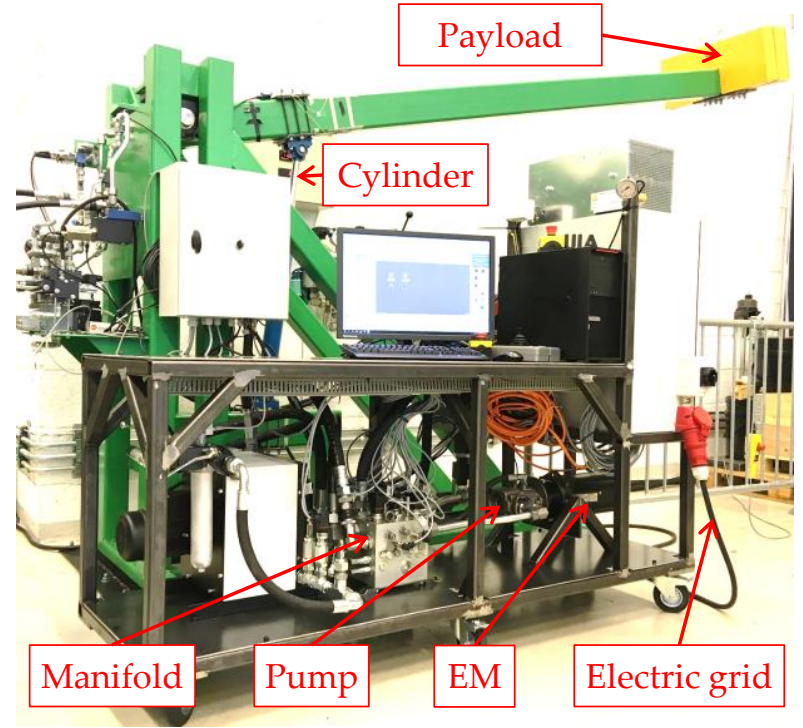

(b)

Figure 1. (a) Simplified schematic of the self-contained cylinder; (b) the experimental setup.

\subsection{Problem Statement}

The control element of this electro-hydraulic system is an electric motor (EM). Its speed (nEM) is commanded to control the piston position $(x)$ by adjusting the flow rate of the hydraulic unit $(\mathrm{P})$. Such an input signal ( $\left.\mathcal{L E M}_{\mathrm{M}}\right)$ is ty pically generated in two alternative ways with respect to $x$ :

1) In open-loop (the system operator defines $и \in M$ directly, for instance using a joystick).

2) In closed-loop (an algorithm calculates $\mathcal{U E M}_{\mathrm{m}}$ to track the commanded piston position based on the measured position error).

Enabling the motion of the actuator requires disengaging the load-holding valves. A reduced drop of about $1.2 \mathrm{~mm}$ was observed in the actuator position during this operation with closed-loop position control [22]. Such a negligible position variation is amplified when the system is operated in open-loop and might become undesired. So, this paper only considers operations in open-loop position control where $\mathcal{U E M ~}_{\mathrm{is}}$ obtained by using velocity feedforward (this aspect will be clarified later). The w orking cycle that w as chosen concerns lifting the crane against a resistant load and then low ering it with an overrunning load. Knowing the desired motion (Figure 2a), the corresponding piston velocity generates the commanded motor speed (Figure $2 b$ ) using only feedforw ard control. Right after disengaging the LHVs (i.e., their dimensionless command becomes 1 in Figure $2 \mathrm{c}$ and $2 \mathrm{~d}$ ), the position drop of the actuator increases up to $2.5 \mathrm{~mm}$ when extending the piston from the position $x_{c, 0}=50 \mathrm{~mm}$ (Figure 2e), or up to $4 \mathrm{~mm}$ before retracting the piston from $x_{c, 0}=440 \mathrm{~mm}$ (Figure 2f). 
(a)

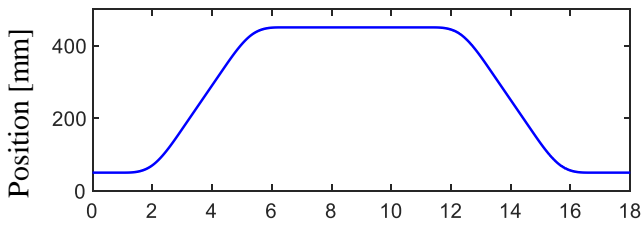

(c)

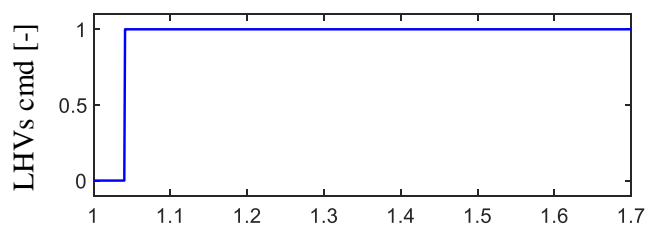

(e)

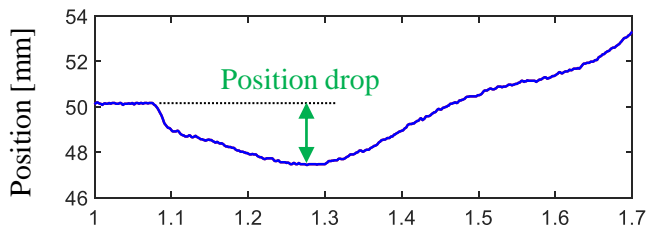

(g)

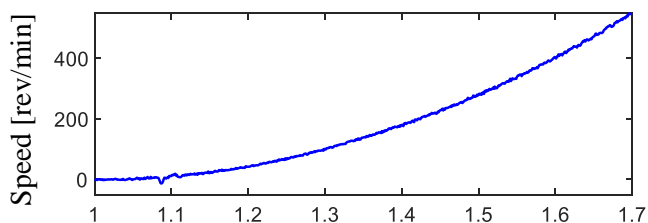

(i)

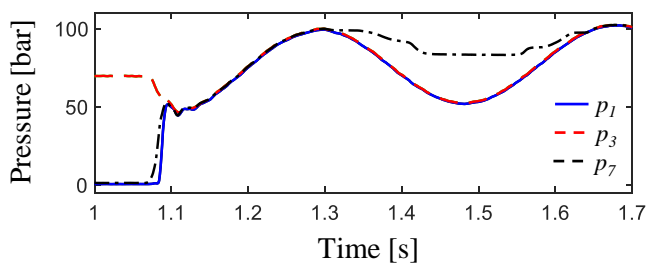

(b)

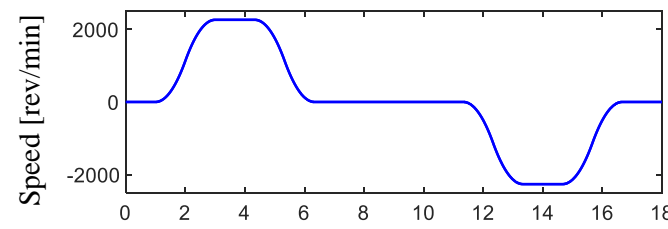

(d)

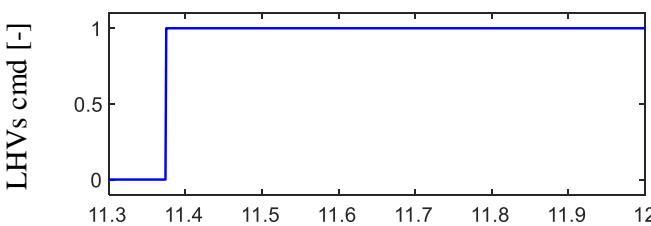

(f)

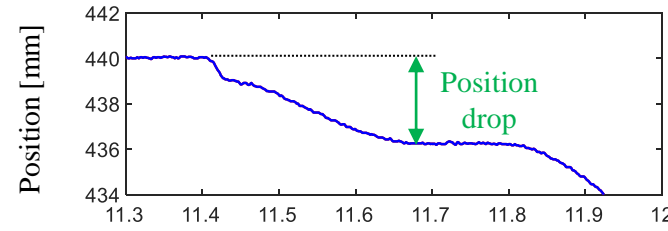

(h)

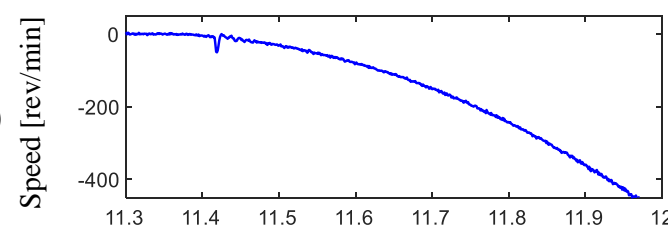

(j)

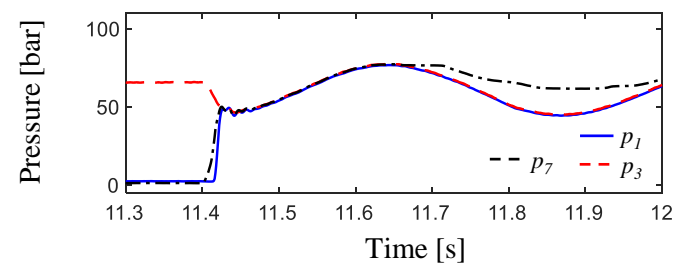

Figure 2. A representative working cycle: (a) desired piston position; : (b) resulting EM's speed command; (c) and (d) load-holding valve's command; (e) and (f) measured piston position; (g) and (h) measured EM's speed; (i) and (j) measured pressures.

This position drop is dictated by both the dynamics of the electric motor and the difference existing between the pressures in the actuator's piston-side chamber ( $\left.p_{3}\right)$ and in the pump's piston-side $\left(p_{1}\right)$. In fact, the motor speed remains very low when the position drops take place (Figure $2 \mathrm{~g}$ and $2 \mathrm{~h}$ ). The load-carrying pressure ( $\left.p_{3}\right)$ decreases (Figure $2 \mathrm{i}$ and $2 \mathrm{j}$ ) because the initial value of the pump pressures $\left(p_{1}\right)$ is equal to the accumulator pressure due to the leakages in the hydraulic unit.

\subsection{Improved Motion Control Strategy}

The feature proposed in this paper modifies the original control strategy, as detailed in [22], to avoid the drop mentioned above in the piston position when the LHVs are disengaged. This modification of the control algorithm takes place during the transition of the LHVs from closed to open state. The idea behind this process can be described according to the following steps:

- Step 1. Right before opening the LHVs, the electric motor is controlled to build up the pump pressure on the piston-side $\left(p_{1}\right)$ to be equal to the actuator pressure ( $\left.p_{3}\right)$ (i.e., closed-loop pressure control is applied). Note that now the electrovalve (EV) is not energized, so the LHVs' opening pilot $\left(p_{7}\right)$ remains very low and equal to the accumulator pressure ( $\left.p_{5}\right)$.

- Step 2. When the pressure difference between $p_{3}$ and $p_{1}\left(e_{P C, 1}\right)$ becomes smaller than a predefined threshold, the EV is energized, and the objective of the closed-loop pressure control is now compensating for the pressure difference between $p_{3}$ and $p_{7}$ (i.e., the EM is adjusting its speed based on the error $\left.e_{P C, 2}=p_{3}-p_{7}\right)$. 
The control structure with the new pressure control (PC) function is illustrated in Figure 3. It generates the commanded electric motor's speed (nEM) by using the feedforward signal (uFF) that involves the commanded piston velocity (e.g., vRef can be obtained from the joystick command), the bore-side area of the actuator $(A)$, and the displacement of the hydraulic unit $(D)$ :

$$
u_{F F}=\frac{v_{R e f} \cdot A}{D} \text {. }
$$

As pointed out in [22], pressure feedback can also be included to add artificial damping and increase motion performance, especially in closed-loop position control. How ever, to clearly show the proposed pressure control strategy's effect, only open-loop control without pressure feedback is presented in this paper.

Additionally, the controller PC only considers two-quadrant operations to meet the functioning dictated by the crane (i.e., the load-carrying chamber is alw ays located on the piston-side). How ever, the pressure control can be expanded to also deal with high-pressure on the rod-side in case fourquadrant functioning is needed.

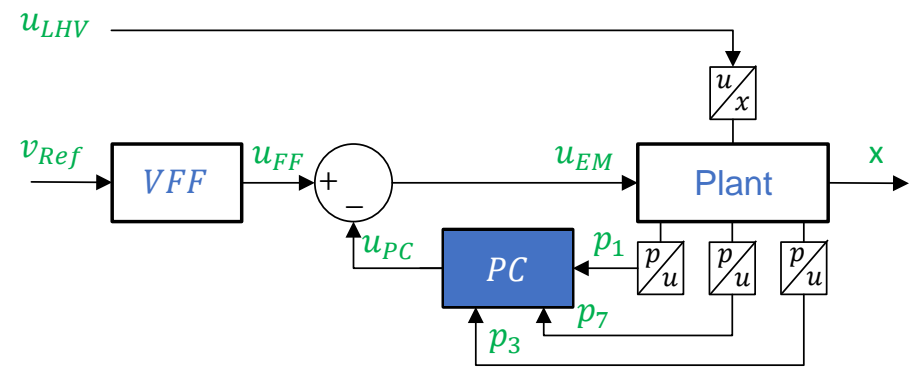

(a)

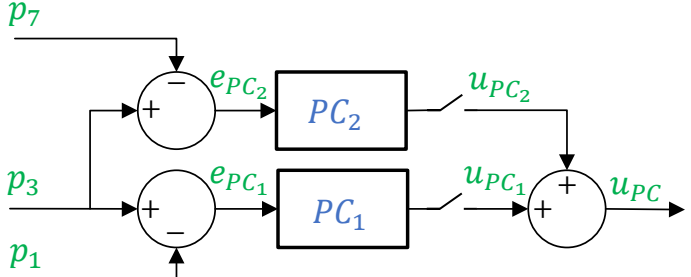

(b)

Figure 1. (a) Proposed control structure of the self-contained cylinder for open-loop position control; (b) detail of the pressure controller.

Pressure control is activated when the piston motion is demanded (i.e., $\left|v_{R e f}\right|>0 \mathrm{~m} / \mathrm{s}$ ) and defines a speed command directed to the EM and consisting of two proportional parts $\left(u_{P C, 1}\right.$ and $\left.U_{P C, 2}\right)$. Before disengaging the LHVs, the pump pressure $\left(p_{1}\right)$ is built up, by activating $u P c, 1$, to be equal to the load pressure $\left(p_{3}\right)$ :

$$
u_{P C, 1}=\left\{\begin{array}{ccc}
\left(p_{3}-p_{1}\right) \cdot k_{P C}, & \text { if }: & \left|v_{R e f}\right|>0 \\
0, & \text { otherwise }
\end{array} .\right.
$$

When the difference $\left|p_{3}-p_{1}\right|$ becomes less than 0.5 bar, then $u_{P C, 2}$ comes into play

$$
u_{P C, 2}=\left\{\begin{array}{c}
\left(p_{3}-p_{7}\right) \cdot k_{P C}, \text { if : }\left|v_{R e f}\right|>0 \text { and }\left|e_{P C, 1}\right|<0.5 \text { bar }, \\
0, \text { otherwise }
\end{array}\right.
$$

and the LHVs are disengaged by energizing the 3/2 electrovalve

$$
u_{\text {LHV }}=\left\{\begin{array}{c}
1, \\
0, \quad \text { otherwise }
\end{array} \text { if } \quad\left|v_{\text {Ref }}\right|>0 \text { and }\left|e_{P C, 1}\right|<0.5\right. \text { bar }
$$

The pressure control signals (i.e., $\mathcal{U P C}_{P} \mathcal{U P C}, 1_{1}$ and $\mathcal{U P C}, 2^{2}$ ) are limited to a maximum of $1000 \mathrm{rpm}$.

\section{Results and Discussion}

The proposed solution to smoothly disengage the load-holding valves with open-loop position control has been experimentally tested with the working cycle presented before (Figure $2 \mathrm{a}$ and $2 \mathrm{~b}$ ). The results are compared to the original measurements in Figure 4 focusing on the initial stage of the piston extension and retraction right after releasing theload-holding valves. 
(a)

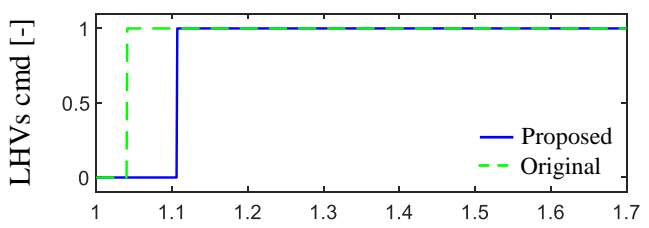

(c)

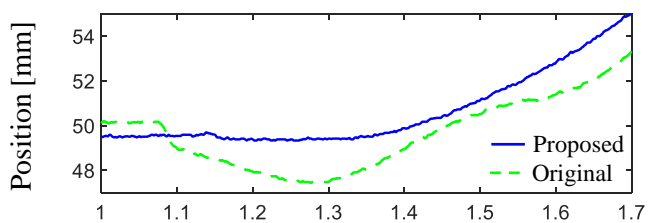

(e)

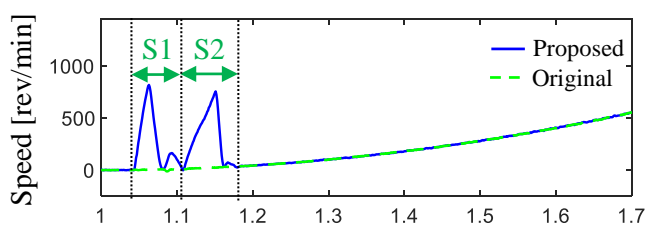

(g)

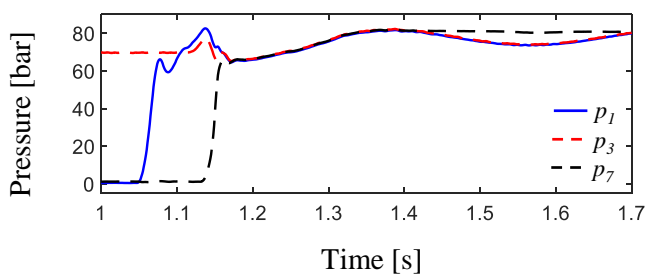

(b)

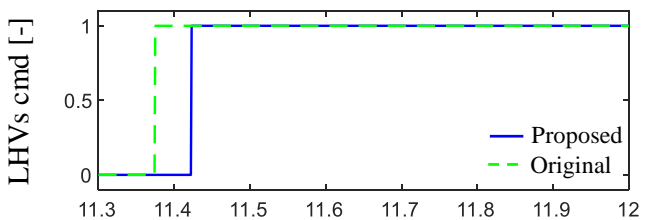

(d)

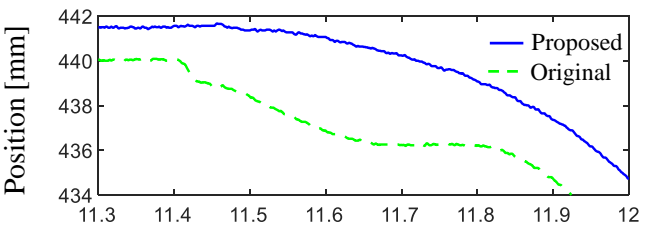

(f)

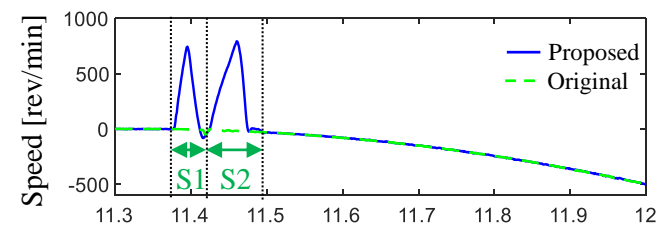

(h)

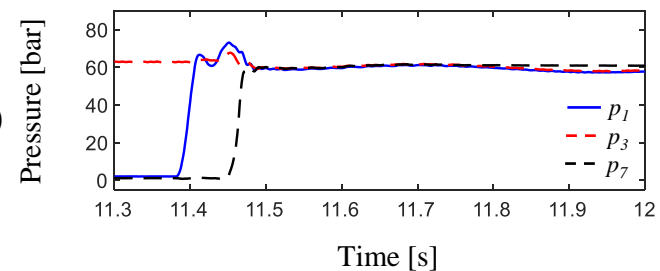

Figure 4. A representative working cycle: (a) and (b) load-holding valve's commands; (c) and (d) measured piston positions; (e) and (f) measured EM's speeds; $(\mathbf{g})$ and (h) measured pre ssures.

Due to the action of the pressure control, the commands to disengage the LHVs are slightly postponed compared to the original scenario (Figure $4 \mathrm{a}$ and $4 \mathrm{~b}$ ) in order to build up the pump side pressure $\left(p_{1}\right)$ to be equal to the actuator pressure $\left(p_{3}\right)$, i.e., pressure control step 1 (S1). Since S1 is not enough to eliminate the drop in the piston position (i.e., a $0.7 \mathrm{~mm}$ drop still occurs), a second control step (S2) was added to make sure that the EM is actively controlled when the opening of the LHVs takes place. Thus, the LHVs are disengaged smoothly and the drop in the piston position is eliminated (Figure $4 \mathrm{c}$ at about 1.14 seconds and Figure $4 \mathrm{~d}$ around 11.45 seconds). The intervention of the prime mover (Figure $4 \mathrm{e}$ and $4 \mathrm{f}$ ) builds up the pressure on the pump port (Figure $4 \mathrm{~g}$ and $4 \mathrm{~h}$ ).

\section{Conclusions}

This paper proposed and experimentally validated a method to smoothly disengage the loadholding valves of a self-contained electro-hydraulic cylinder driving a single-boom crane. The approach involves pressure control and eliminates the piston position's drop that takes place right after energizing the load-holding valves (drops up to $4 \mathrm{~mm}$ were observed). Theses outcomes benefit those systems where the kinematics amplifies the piston motion significantly (e.g., in aerial platforms) increasing, therefore, the operational safety. Motion control in open-loop was considered in this research. How ever, future w ork will address the disengagement of the load-holding valves smoothly when closed-loop position control is required.

Acknowledgments: The authors acknowledge the funding through the Norwegian Research Council projects Motion Lab (245717/F50) and SFI Offshore Mechatronics (237896).

Author Contributions: Conceptualization, D.H. and D.P.; methodology, D.H.; software, D.H.; validation, D.H.; formal analysis, D.H.; investigation, D.H.; data curation, D.H.; writing - original draft preparation, D.H. and D.P.; writing - review and editing, D.H., D.P.; visualization, D.H.; supervision, D.P.

Conflicts of Interest: The authors declare no conflict of interest. 


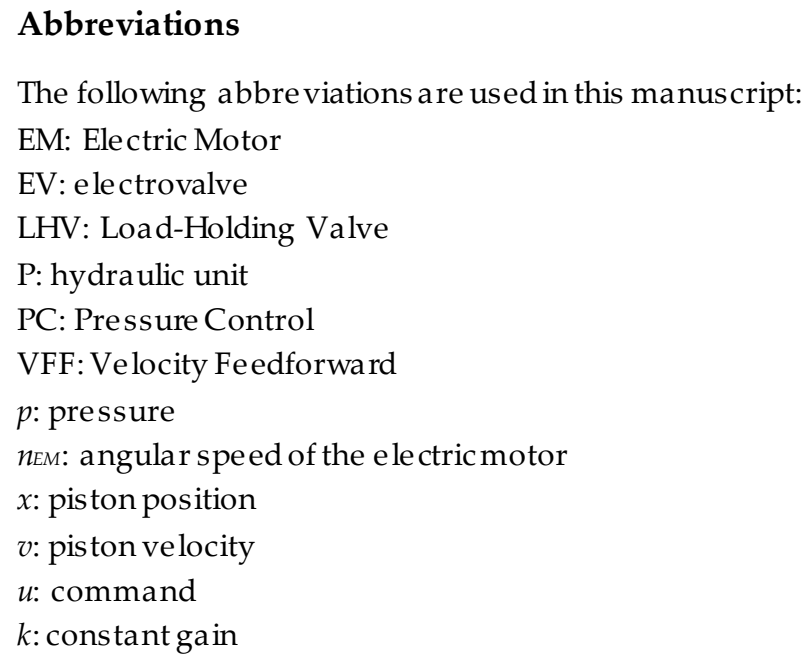

\section{References}

[1] D. Padovani, M. Rundo, and G. Alta re, “The Working Hydraulics of Valve-Controlled Mobile Machines: Classification and Review," ASMEJ. Dyn. Syst. Meas. Control, vol. 142, no. 7, 2020.

[2] R. Rahmfeld and M. Ivantysynova, "Energy Saving Hydraulic Actuators for Mobile Machines," in 1st Bratislavian Fluid Power Symposium, 1998, pp. 177-186.

[3] S. Michel and J. Weber, "Energy-efficient Electrohydraulic Compact Drives for Low Power Applications," ASME/BATH Symp. Fluid Power Motion Control, 2012.

[4] H. Pedersen, L. Schmidt, T. O. Andersen, and M. H. Brask, “Investigation of NewServo Drive Concept Utilizing Two Fixed Displacement Units," in International Symposium on Fluid Power, 2014.

[5] L. Schmidt, D. Roemer, H. Pedersen, and T. Andersen, "Speed-Variable Switched Differential Pump System for Direct Operation of Hydraulic Cylinders," in ASME/BATH Symposium on Fluid Power and Motion Control, 2015.

[6] L. Schmidt, M. Groenkjaer, H. Pedersen, and T. Andersen, “Position Control of an Over-Actuated Direct Hydraulic Cylinder Drive," Control Eng. Pract., vol. 64, no. December 2016, pp. 1-14, 2017.

[7] T. Minav, J. Heikkinen, and M. Pietola, “Direct Driven Hydraulic Drive for New Powertrain Topologies for Non-Road Mobile Machinery," Electr. Power Syst. Res., vol. 152, pp. 390-400, Nov. 2017.

[8] P. Gøytil, D. Padovani, and M. Hansen, “On the Energy Efficiency of Dual Prime Mover PumpControlled Hydraulic Cylinders," in ASME/BATH Symposium on Fluid Power and Motion Control, 2019.

[9] S. Michel and J. Weber, "Energy-efficient Electrohydraulic Compact Drives for Low Power Applications," ASME/BATH Symp. Fluid Power Motion Control, pp. 93-107, 2012.

[10] S. Michel and J. Weber, "Electrohydraulic Compact-drives for Low Power Applications considering Energy-efficiency and High Inertial Loads," 7th FPNI PhD Symp. Fluid Power, pp. 1-18, 2012.

[11] G. Altare, A. Vacca, and C. Richter, “A Novel Pump Design for an Efficient and Compact ElectroHydraulic Actuator," in IEEE Aerospace Conference, 2014.

[12] G. Altare and A. Vacca, "A Design Solution for Efficient and Compact Electro-hydraulic Actuators," Procedia Eng., vol. 106, no. 8, 2015.

[13] H. Çalışkan, T. Balkan, and B. Pla tin, "A Comple te Analysis for Pump Controlled Single Rod Actua tors," in 10th International Fluid Power Conference, 2016.

[14] D. Hagen, D. Padovani, and M. K. Ebbesen, "Study of a Self-Contained Electro-Hydraulic Cylinder Drive," in Global Fluid Power Society PhD Symposium (GFPS), 2018.

[15] D. Padovani, S. Ketelsen, D. Hagen, and L. Schmidt, “A Self-Contained Electro-Hydraulic Cylinder with 
Passive Load-Holding Capability," Energies, vol. 12, no. 2, p. 292, 2019.

[16] S. Qu, D. Fassbender, A. Vacca, B. Enrique, and U. Neumann, "A Closed Circuit Electro-Hydraulic Actuator with Energy Recupe ration Capability," in 12th International Fluid Power Conference, 2020.

[17] T. Minav, S. Panu, and P. Matti, “Direct-Driven Hydraulic Drive Without Conventional Oil Tank," in ASME/BATH Symposium on Fluid Power and Motion Control, 2014.

[18] L. Schmidt, S. Ketelsen, M. Brask, and K. Mortensen, “A Class of Energy Efficient Self-Contained Ele ctroHydraulic Drives with Self-Locking Ca pability," Energies, vol. 12, no. 10, 2019.

[19] L. Schmidt, S. Ketelsen, D. Padovani, and K. Mortensen, "Improving the Efficiency and Dynamic Properties of a Flow Control Unit in a Self-Locking Compact Electro-Hydraulic Cylinder Drive," ASME/BATH Symp. Fluid Power Motion Control, 2019.

[20] S. Ketelsen, D. Padovani, T. O. Andersen, M. K. Ebbesen, and L. Schmidt, “Classification and Re view of Pump-Controlled DifferentialCylinder Drives," Energies, vol. 12, no. 7, 2019.

[21] D. Hagen, D. Padovani, and M. Choux, "A Comparison Study of a Novel Self-Contained ElectroHydraulic Cylinder versus a Conventional Valve-Controlled Actuator - Part 2: Energy Efficiency," Actuators, vol. 8, no. 78, 2019.

[22] D. Hagen, D. Padovani, and M. Choux, "A Comparison Study of a Novel Self-Contained ElectroHydraulic Cylinder versus a Conventional Valve-Controlled Actuator - Part 1: Motion Control," Actuators, vol. 8, no. 79, 2019.

(C) 2020 by the authors; licensee MDPI, Basel, Switzerland. This article is an open access article distribute $\mathrm{d}$ under the terms and conditions of the Creative Commons by Attribution (CC-BY) license (http://creativecommons.org/licenses/by/4.0/). 